\title{
STATE-OF-THE-ART Neonatal lung ultrasound exam guidelines
}

\author{
D Kurepa ${ }^{1}$, N Zaghloul ${ }^{1}$, L Watkins ${ }^{2}$ and $\mathrm{J} \mathrm{Liu}^{3}$
}

Point-of-care ultrasound (POC-US) is increasingly used especially in emergency and critical-care medicine. It is focused, quick and does not expose patients to ionizing radiation. It encompasses all organ systems and has well-defined indications. Lung ultrasound (LUS) represents one of the most exciting applications in the field of POC-US. It is particularly important to emphasize the role of LUS in neonatology due to the specific pathology inherent in lung immaturity as well as in the particular sensitivity of neonates to repeated radiation exposure. One of the main barriers to the more extensive use of the ultrasound technology is a lack of efficient and attractive training solutions followed by the structured quality-check assurance. In an effort to help bridge this gap, based on the most current literature, we developed creative and intuitive neonatal LUS algorithms. We hope they can serve as a clinical imaging guidelines and a valuable complement to the history and physical exam.

Journal of Perinatology (2018) 38, 11-22; doi:10.1038/jp.2017.140; published online 16 November 2017

\section{INTRODUCTION}

In the past several years lung ultrasound (LUS) has become one of the most exciting applications in the field of the neonatal point-ofcare ultrasound (POC-US). Several recent articles have found ultrasound imaging to be an equal, if not a more effective diagnostic modality than X-ray. LUS is quicker, less expensive and it does not expose patients to the increased risks inherent in exposure to ionizing radiation. ${ }^{1}$

One of the challenges to widespread use of LUS is a paradigm shift in which physicians have to accept a fundamentally different way of thinking. Therefore, there is a need to develop creatively engaging strategies that would allow us this practice transition. Clinical guidelines modeled through decision-making algorithms have proven to simplify diagnostic and management processes. LUS algorithms or protocols have been described in the adult population. ${ }^{2}$ They cover vast amount of data and knowledge that are well validated and reproducible. On the other hand, no such algorithm exists for the neonatal population known to have relatively specific lung pathology. Acknowledging this fact, we reviewed neonatal LUS literature and developed neonatal LUS algorithms that serve as guidelines for LUS application in the neonatal population (Figure 1 and 2). The goal is to better help neonatologists embrace the daily use of the ultrasound as a diagnostic modality. Further, the algorithms should allow neonatologists to transfer their insights and experiences into new research ideas and better patient outcomes.

\section{TECHNICAL ASPECTS}

High-frequency (10 MHz or higher) linear transducer is used most commonly. Lung preset is set on the ultrasound machine.

Lung US exam is performed on a neonate in the incubator or on the radiant warmer. The transducer is oriented in a sagittal plane. Bilateral lungs are examined in the supine and lateral positions. In addition, prone position is commonly used. Each side is divided into three areas: anterior area between sternum and anterior axillary line, lateral area between anterior and posterior axillary line and posterior area between the posterior axillary line and the spine. ${ }^{3}$ In adults, an image map of the lungs created with the use of the ultrasound has been found to have a much higher sensitivity and specificity than the physical exam or chest radiography. ${ }^{4,5}$

\section{CURRENT NEONATAL LUS LITERATURE}

Current neonatal lung literature describes the normal and abnormal LUS imaging based on the several principles described by Lichteinstein and Mauriat. ${ }^{6}$ There are few articles that summarize neonatal findings, encourage LUS use and offer insights into further research. ${ }^{3,7,8}$ Aside from diagnosing specific lung diseases, ultrasound has shown a great promise in the functional monitoring of lung processes and predicting the development of complications. ${ }^{9-16}$

\section{NORMAL NEONATAL LUS PATTERNS}

Neonatal LUS examination follows the same principles as adult ultrasound. As already mentioned, lung image map is created by interrogation of the pleural surfaces at three sites over each hemithorax.

\section{Anatomy}

Rib cage consists of the skin, subcutaneous tissue and muscles that overlie the ribs. Below the ribs are parietal and visceral pleura that slide against each other with every respiration. Multiple interlobular septae arise from the visceral pleura and create lobules that consist of many alveolar acini filled with air. In a healthy lung, air completely scatters ultrasound waves.

\section{Pleural line}

A curvilinear, brightly echogenic and smooth line that originates from the reflection of the pleural surface is called pleural line. Together with the two adjacent rib shadows this line forms a "bat

\footnotetext{
'Division of Neonatal-Perinatal Medicine, Cohen Children's Medical Center, New Hyde Park, NY, USA; ${ }^{2}$ Division of Pediatric Critical Care, Cohen Children's Medical Center, New Hyde Park, NY, USA and ${ }^{3}$ Department of Neonatology and NICU, Beijing Chaoyang District Maternal and Child Health Care Hospital, Beijing, China. Correspondence: Dr D Kurepa, Division of Neonatal-Perinatal Medicine, Cohen Children's Medical Center, 269-01 76th Avenue, Suite 344, New Hyde Park, NY 11040, USA. 


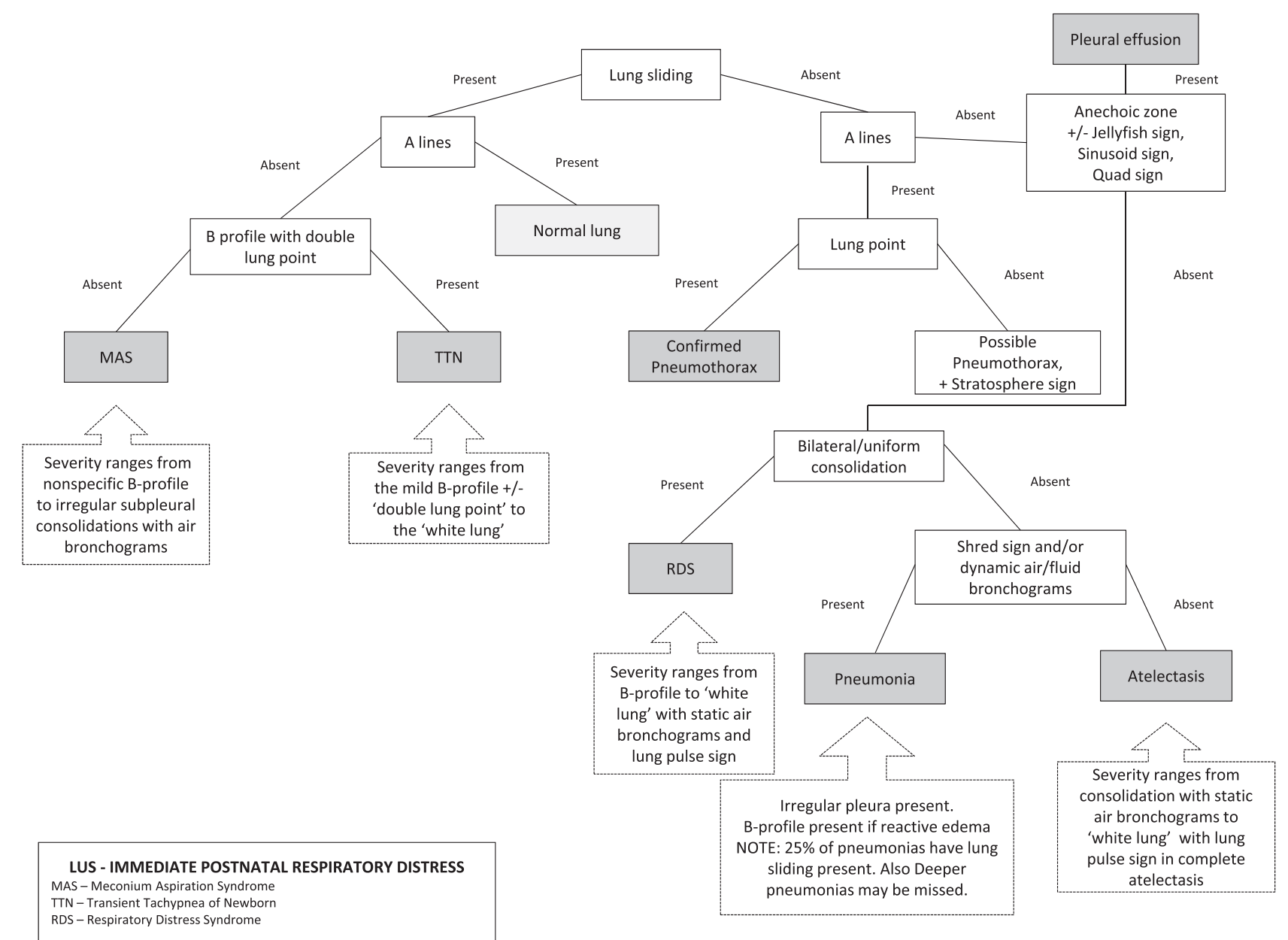

Figure 1. Algorithm 1 is shown. LUS - Immediate postnatal respiratory distress.

sign' (Figure 3a). ${ }^{6}$ Obtaining this sign assures that the probe is perpendicular to the thorax and allows capturing adequate images.

\section{Lung sliding}

Movement of the parietal against the visceral pleura during respiration is called 'lung sliding'. ${ }^{17}$ This dynamic phenomenon appears as a shimmering line and it is indicative of a healthy lung. In the M-mode image appears as a linear pattern in the tissues superficial to the pleural line ('sea') and a grainy or 'sandy' appearance deeper to the pleural line ('shore') creating the 'seashore sign' (Figure 3a and Supplementary Video S1). ${ }^{18}$

\section{A-lines}

A-lines are horizontal, hyperechogenic, equidistant lines distal to the pleural line. It is a reverberation artifact due to the ultrasound waves being repetitively reflected between the pleura and the transducer (Figure 3b). ${ }^{6}$ A-line pattern together with lung sliding assures the absence of lung pathology in the area of the lung scanned.

\section{ABNORMAL LUS PATTERNS}

Obtained pleural line artifacts highly correlate with the underlying pathology.
B-lines

B-lines are vertical, hyperechoic lines extending from pleura distally to the far field without fading. They erase A-lines and move synchronously with the lung sliding (Figure 4). The origin of this phenomenon is accumulation of the lung fluid that widens interlobular septae. Increased presence of the fluid may be due to pneumonia, pulmonary edema and transient tachypnea of the newborn (TTN). It may be normal in newborns in the first $48 \mathrm{~h}$, or longer in premature infants, until the lung fluid completely resorbs. On the other hand, B-lines may also be present in chronic lung disease that causes scarring of the septae. Depending on the pathology, B-lines may be unilateral (pneumonia) or bilateral (pulmonary edema, TTN). ${ }^{19}$

\section{Lung consolidation}

The origin of the lung consolidation pattern is any process that leaves the alveoli without air or filled with fluid. Most common causes are atelectasis (Figure 5), pneumonia and severe pulmonary edema. Ultrasound appearance of the consolidated lung gives tissue-like density or, so-called, 'hepatinization of the lung'. An adult study conducted on 65 cases of alveolar consolidation and 53 CT scan controls showed sensitivity and specificity of ultrasound to be $90 \%$ and $98 \%$, respectively. Kappa coefficient for concordance was $0.89 .^{20}$ Nevertheless, this finding is entirely descriptive, and additional information is needed to further delineate the origin of the consolidation. 


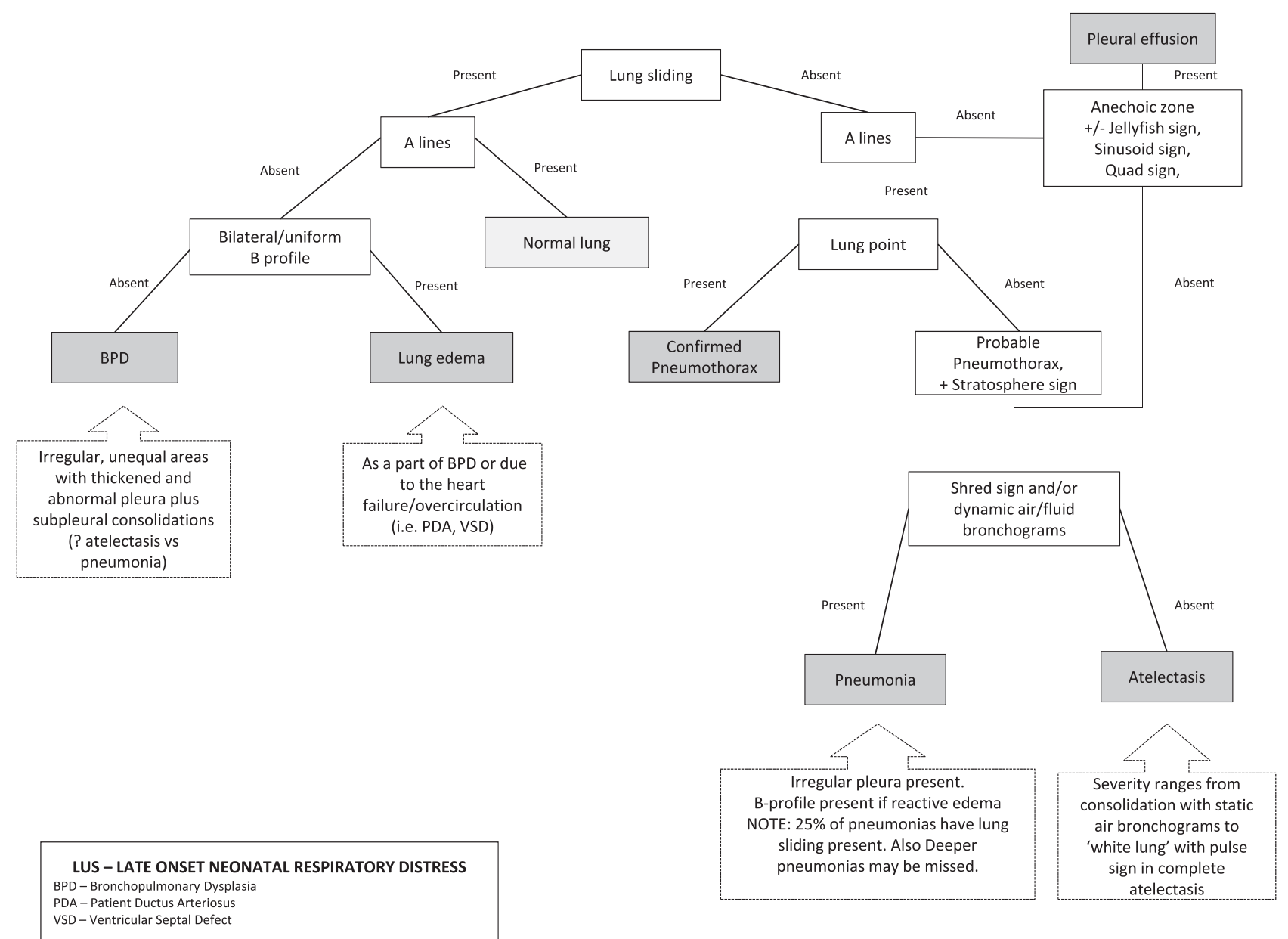

Figure 2. Algorithm 2 is shown. LUS - Late onset neonatal respiratory distress.

\section{SPECIFIC LUNG DISEASES}

Transient tachypnea of the newborn

TTN is the common cause of respiratory distress in the immediate postnatal period. It is the result of a delay in the clearance of the fetal lung liquid and, therefore, also called 'wet lung'. LUS imaging in TTN shows a spectrum of patterns from 'white lung' to the prevalence of B-lines and to the most benign pattern of the A-line prevalence. Most commonly, but not always, these patterns are equal bilaterally. On the basis of these LUS findings, one study of 154 infants admitted to neonatal intensive care unit showed that LUS has sensitivity of $77.7 \%$, specificity of $100 \%$, Positive Predictive Value (PPV) of $100 \%$ and Negative Predictive Value (NPV) of $97 \%$ in predicting the need for respiratory support. ${ }^{12}$ On the other hand, in the longitudinal scan of the lungs carried out on 32 infants with TTN and 60 healthy controls, finding of the 'double lung point' (difference in the upper and lower lung field images) is $100 \%$ sensitive and specific for TTN (Figure 6). ${ }^{21}$ In another larger study it was found that 'double lung point' is $76.7 \%$ sensitive and $100 \%$ specific where lower sensitivity was attributed to the group of the severe TTN neonates who had 'white lung' appearance that obliterated the transition between upper and lower lung fields. ${ }^{22}$ The most recent study that explored LUS findings in TTN found that 'double lung point' is $45.6 \%$ sensitive and $94.8 \%$ specific finding in TTN. It is found mainly in milder cases of TTN, whereas 'white lung' and 'B-line pattern' signify more severe disease. ${ }^{23}$ LUS, studied in 59 infants, has also shown great sensitivity and specificity in differentiating $\mathrm{TTN}$ from respiratory distress syndrome (RDS). ${ }^{24}$
Respiratory distress syndrome

Neonatal RDS is an extremely common cause of respiratory distress and/or failure in the neonatal intensive care unit. It is a manifestation of the lung immaturity and lack of surfactant. Several studies examined the use of LUS in the diagnosis and evaluation of RDS. Initially, Avni et al. used abdominal approach to examine the lung in 40 premature infants. They found retrohepatic area to be highly hyperechogenic in babies with RDS with the improvement as the disease improves. ${ }^{25}$ Later, longitudinal scans of the lung have shown bilateral 'white lung' appearance with no 'spared areas'. Pleural line is thick, irregular with small subpleural consolidations (Figure 7). ${ }^{26}$ Few well-designed studies examined the accuracy of the LUS in almost 200 premature infants with clinical and X-ray RDS diagnosis. They have found sensitivity, specificity, PPV and NPV to be consistently well above $90 \%$ in both retrohepatic and longitudinal scanning approach. ${ }^{27-29}$ Furthermore, LUS has been increasingly studied as an evaluation tool in predicting complications of RDS (pneumothorax, hemorrhage, atelectasis and bronchopulmonary dysplasia (BPD)) and has proven to be a very promising alternative to chest X-rays. ${ }^{30-32}$

\section{Pneumothorax}

As previously mentioned, ultrasonography of the healthy lung reveals 'lung sliding' and 'seashore sign' on B- and M-mode imaging, respectively. In cases of pneumothorax, however, the presence of air between visceral and parietal pleura abolishes lung sliding on the B-mode imaging. In a study group of 43 pneumothoraces and 68 healthy controls, sensitivity and 


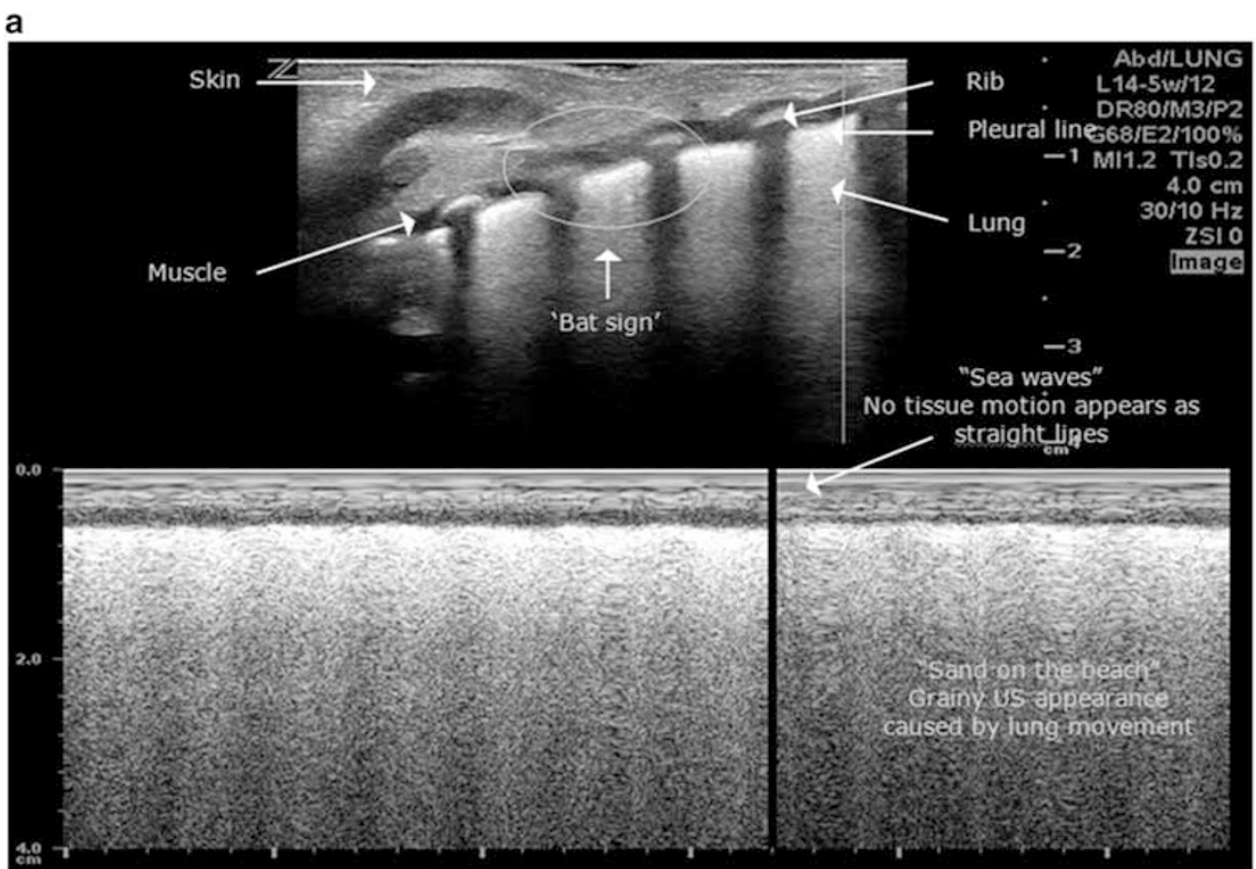

b

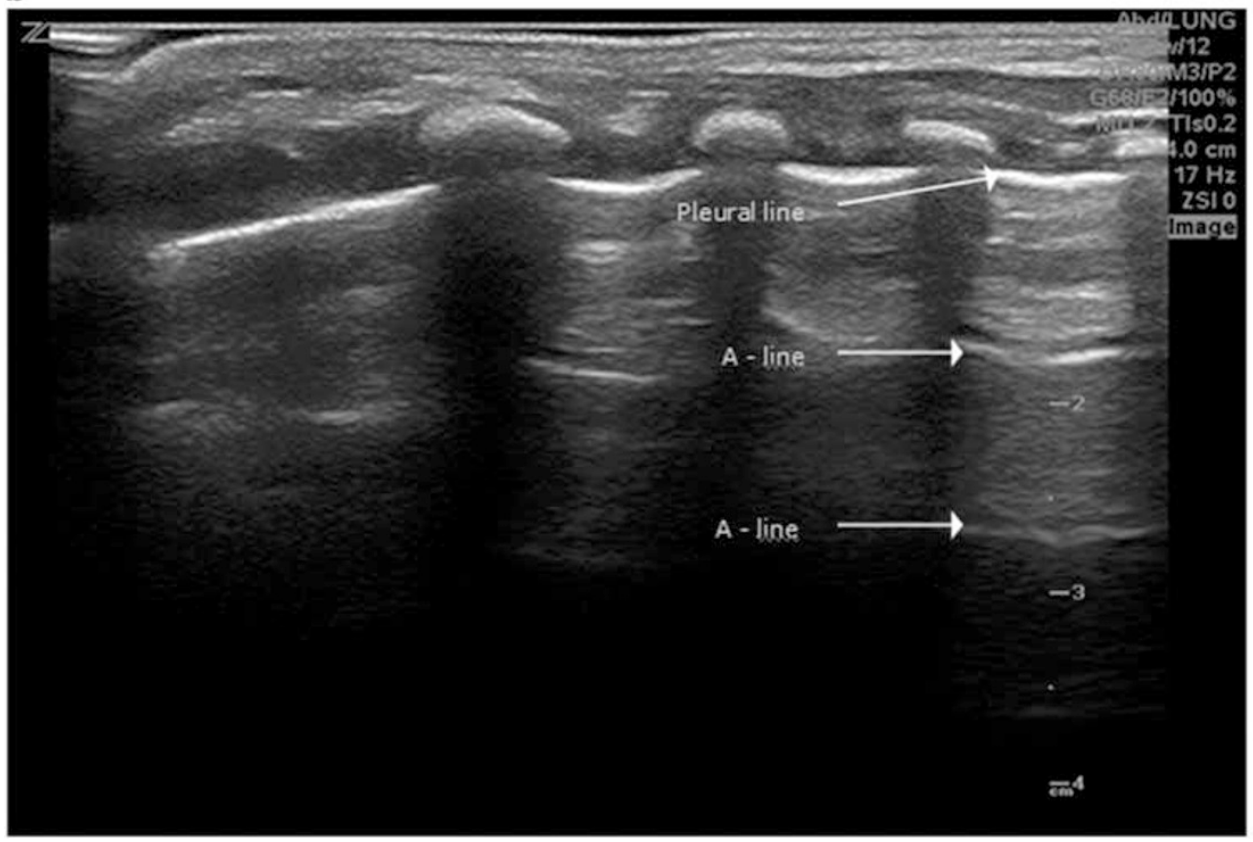

Figure 3. (a) 'Bat sign' (upper part of the image) and 'Seashore sign' (lower part of the image). Normal neonatal lung on B-mode imaging shows 'bat sign'. Two adjacent ribs with posterior shadowing represent the wings of the bat, with the body represented by the echogenic pleural line. Normal neonatal lung on M-mode imaging shows 'seashore sign'. Echogenic pleural line divides the image in the motionless part represented by horizontal lines ('sea waves') and the part below that appears granular ('sand') as the normal to- and fro-motion of the lung is reflected over that area. (b) A-lines. Equidistant, horizontal and echogenic lines distal to the pleural line. Presence of lung sliding together with A-lines indicates normal neonatal lung in the area scanned.

specificity of this sign was $95.3 \%$ and $91.1 \%$ with NPV of $100 \%$, respectively. ${ }^{17} \mathrm{M}$-mode imaging reveals 'barcode or stratosphere sign'. In obtaining an optimal 'barcode sign' it is recommended to use lower frequency probe $(10 \mathrm{MHz}$ or lower) as shown in the Figures $8 a$ and $b$ comparison (Figures $8 a$ and $b$ and Supplementary Video S2). B-lines cannot be seen as they originate from the visceral pleura. When present, B-lines have almost $100 \%$ NPV for pneumothorax. ${ }^{18}$ Another well-described sign is 'lung point'. It represents the transitional zone between normal (lung sliding) and abnormal (no lung sliding) lung pattern (Figure 9 and Supplementary Video S3). In adult study on 66 patients with pneumothorax, it was not very sensitive, especially in larger pneumothoraces, but when found it is $100 \%$ specific for pneumothorax. ${ }^{33}$ The correct sequence in using above-mentioned signs for diagnosing pneumothorax has been described. ${ }^{34}$ This sequence is present in our algorithm as well. 


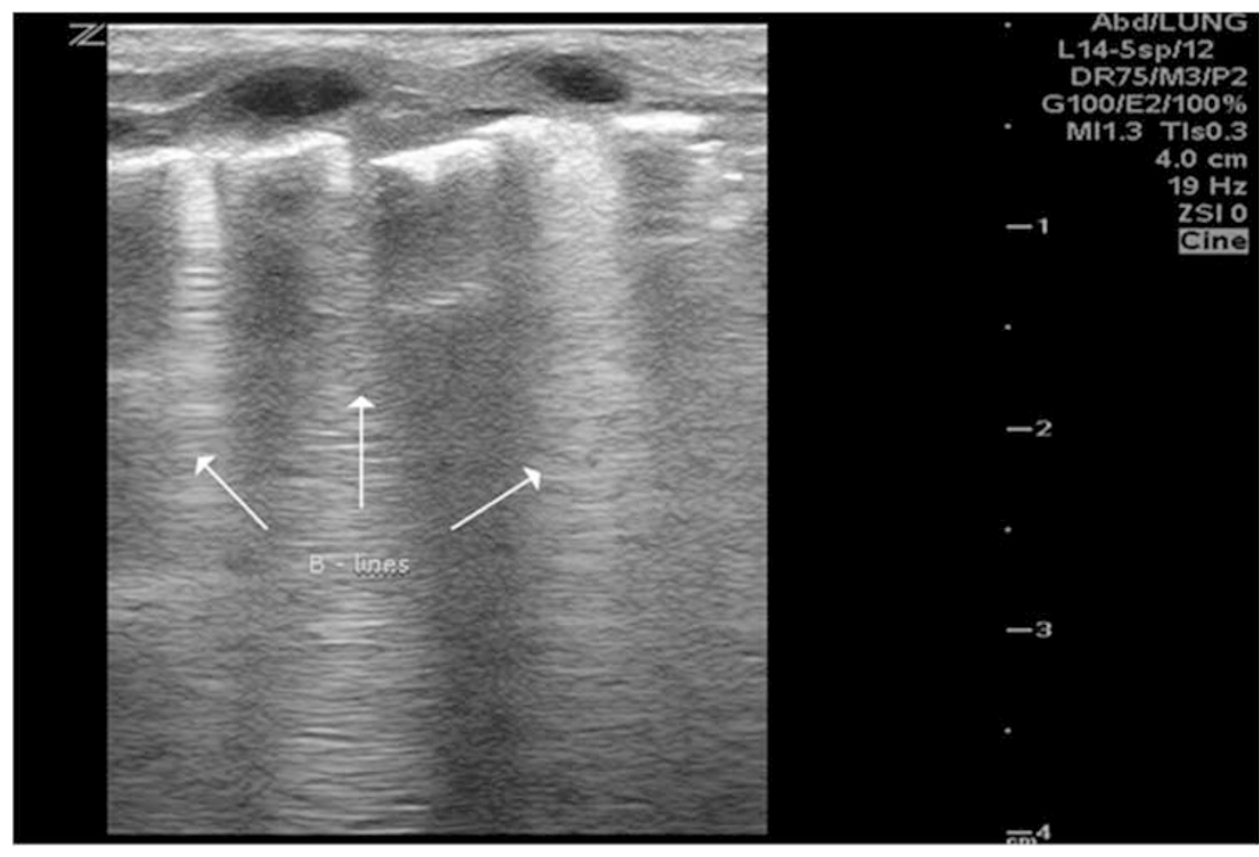

Figure 4. B-lines. B-lines are vertical hyperechoic, 'laser-like bundles' extending from pleura to the edge of the ultrasound screen. They erase A-lines. They are generated when subpleural interlobular septa are filled with fluid (that is, transient tachypnea of the newborn (TTN)) and therefore widened.

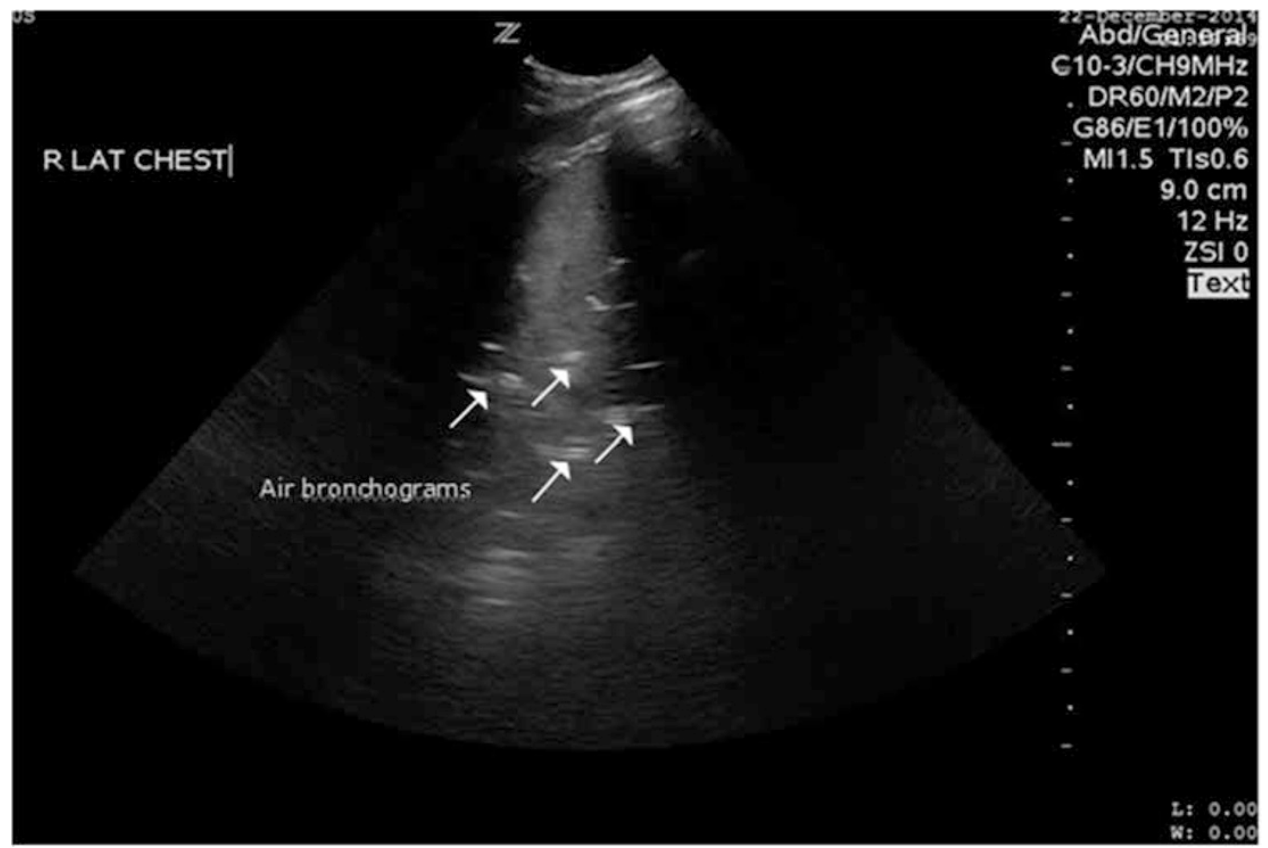

Figure 5. Consolidation. In neonates, lung consolidation usually appears isoechoic with the liver ('hepatinization of the lung'). Consolidation may be of different sizes and shapes. It erases both the pleural line and A-lines. It is characterized by the presence of tiny, hyperechoic lines called air bronchograms.

\section{Pneumonia}

LUS is a useful diagnostic tool in the evaluation of pediatric pneumonia. ${ }^{34}$ In pneumonia alveoli are filled with the inflammatory exudate. They can also collapse as the smaller airways are plugged with the cellular debris. Because of lack of air in the alveoli, propagation of the ultrasound waves is facilitated. On the LUS, pneumonia gives rise to sonographic consolidation profile or 'lung hepatinization' as it resembles the liver tissue. Pleural line is irregular, coarse and hypoechoic in $90 \%$ of the cases. Lung sliding is absent in $75 \%$ of cases. Approximately one-third of the patients will have pleural effusion (an anechoic area below the pleural surface). Below pleura, infected lung looks hypoechoic with irregular borders. Recent study of 40 neonates with clinically and X-ray-proven pneumonia and 40 healthy controls found that 


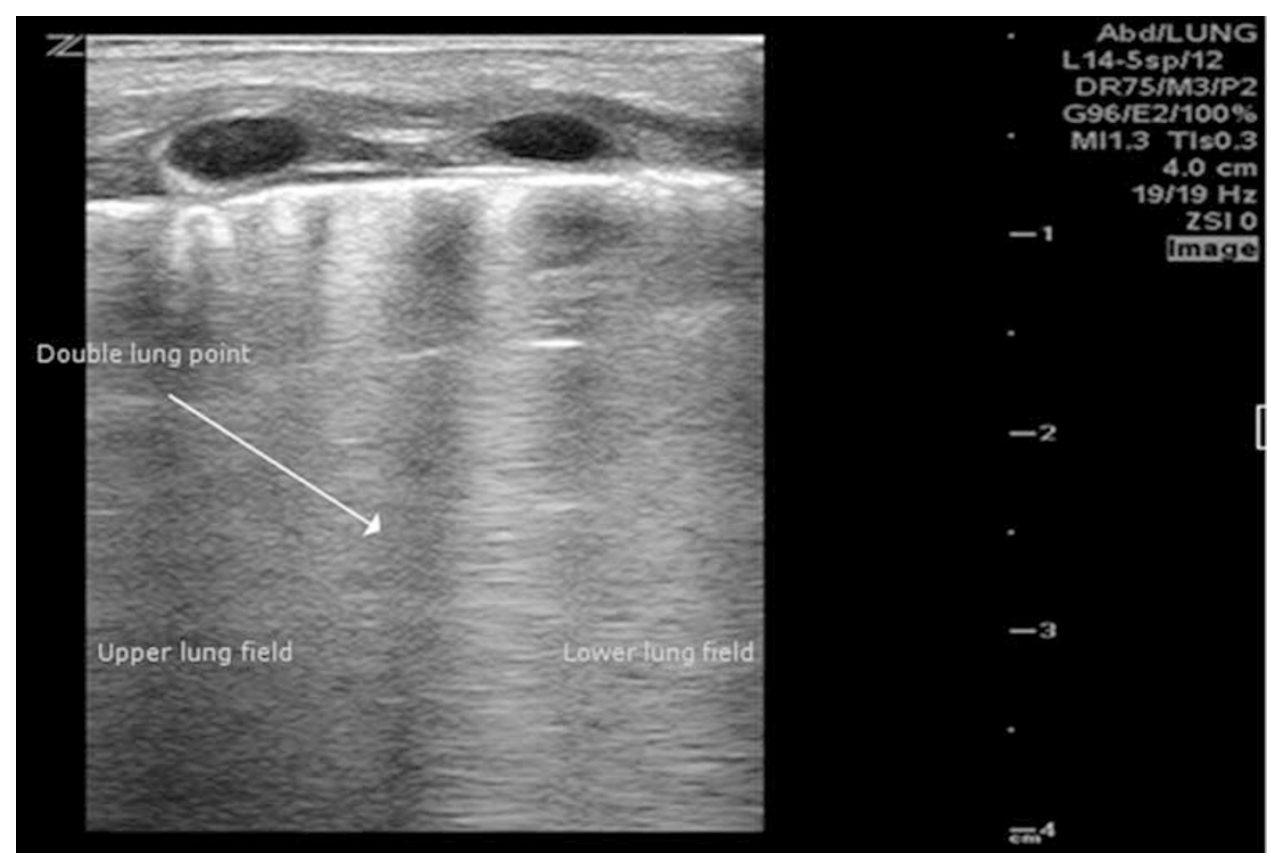

Figure 6. Transient tachypnea of the newborn (TTN) with 'double lung point'. In TTN 'double lung point' represents the difference in lung echogenicity between the upper (improved) and lower (still 'wet') lung fields.

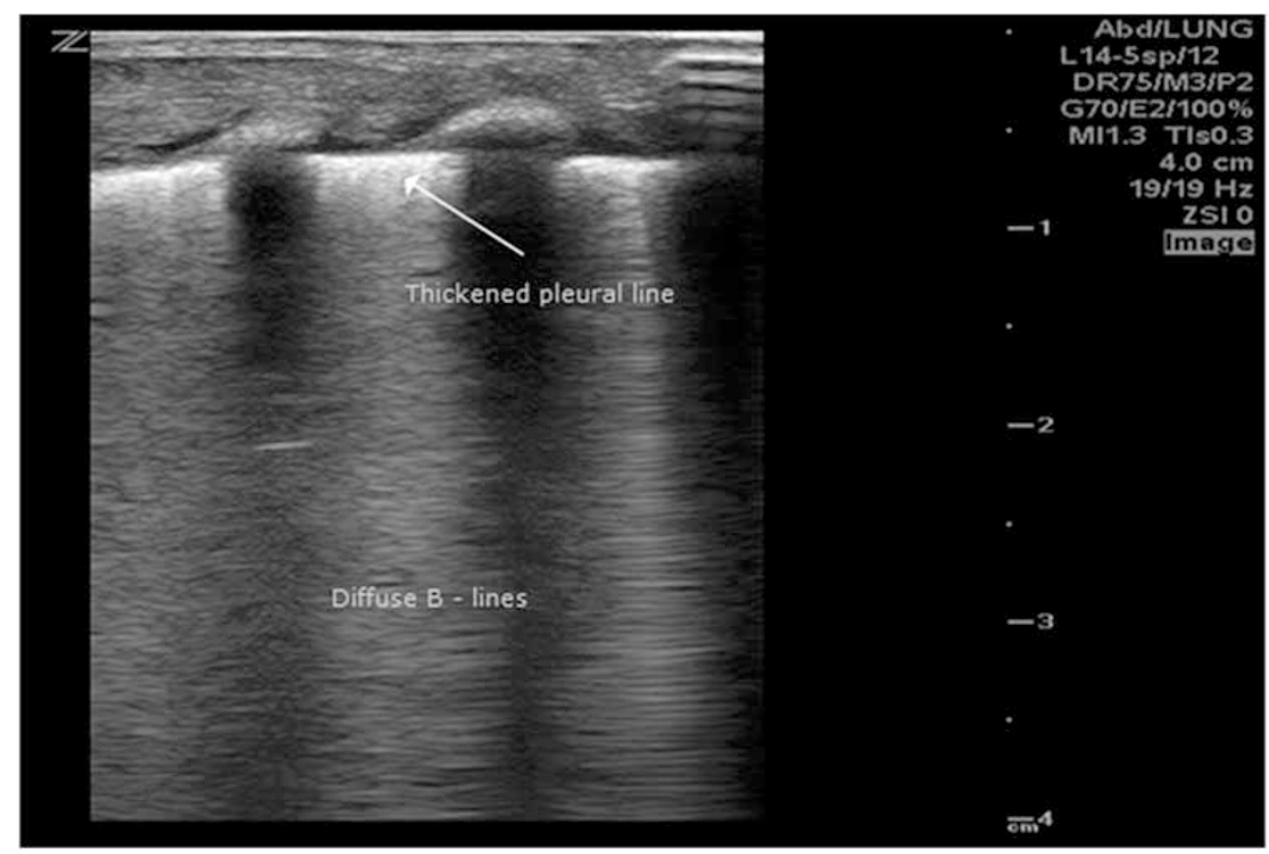

Figure 7. Mild respiratory distress syndrome. Lung ultrasound in a 27-week premature neonate showing thickened pleural line with subpleural atelectasis and multiple, compact B-lines. A-lines are absent.

larger lung area of consolidation with irregular margins has $100 \%$ sensitivity and $100 \%$ specificity for the diagnosis of neonatal pneumonia. A-lines disappear. ${ }^{35}$ Importantly, most of pneumonia consolidations show dynamic air bronchograms scattered throughout the affected area. They are hyperechoic, linear inclusions of air that are trapped inside smaller airways that move with respirations. If the reactive edema around the affected area is pronounced, B-lines will be present. It is essential to note that the smaller infectious consolidations that do not reach the pleural surface may be missed on the LUS. ${ }^{35,36}$

\section{Atelectasis}

Resorptive atelectasis is commonly found in neonates on mechanical ventilation due to the insufficient ventilator pressures. Another common reason is obstructive atelectasis caused by increased secretions, pulmonary hemorrhage or infectious exudate. Rarely, compressive atelectasis can be seen in patients with pleural effusions. As mentioned before, on the LUS atelectasis appears as consolidation with clear borders. Pleural line abnormalities exist in all patients with lung sliding absent in $60 \%$ of cases. A-lines are erased. 'Lung pulse' is mostly present in atelectasis of a bigger size. 
a

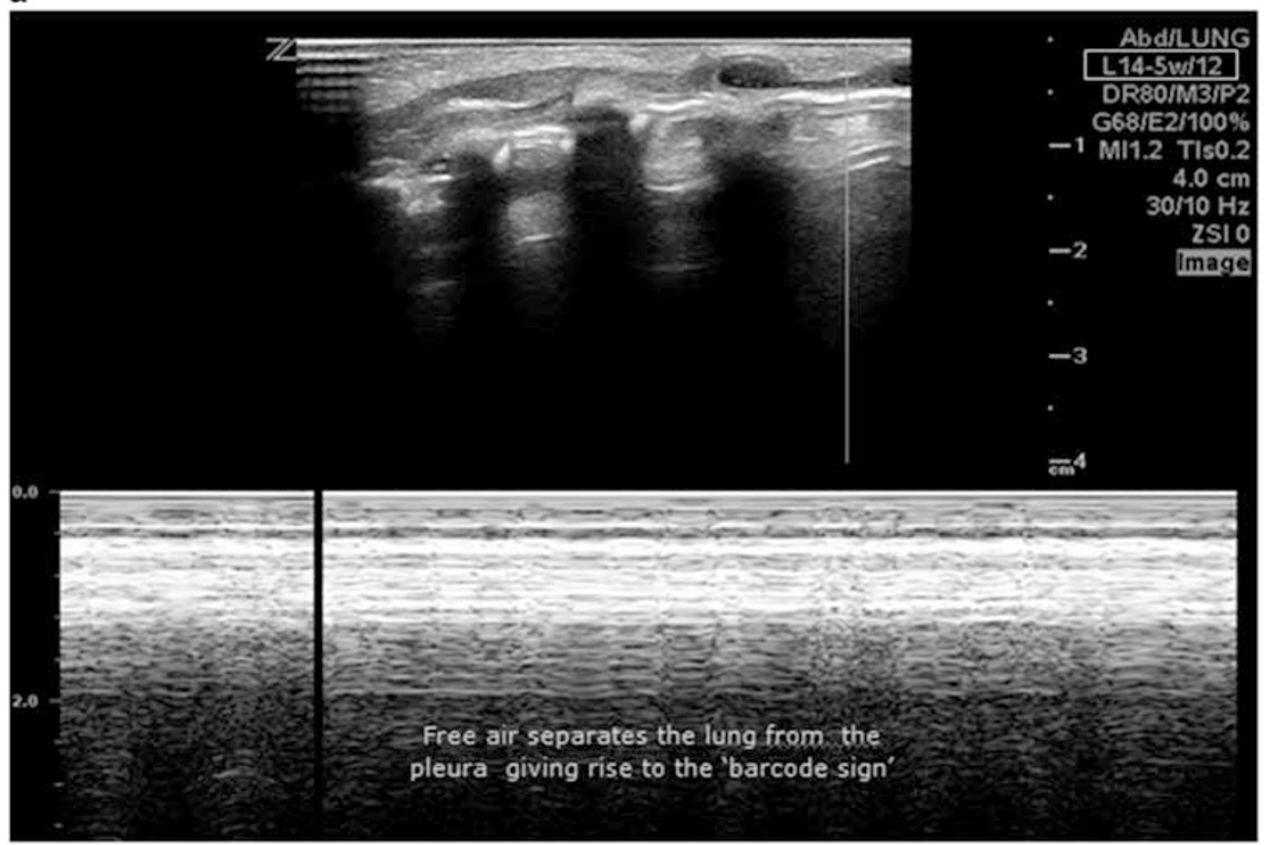

b

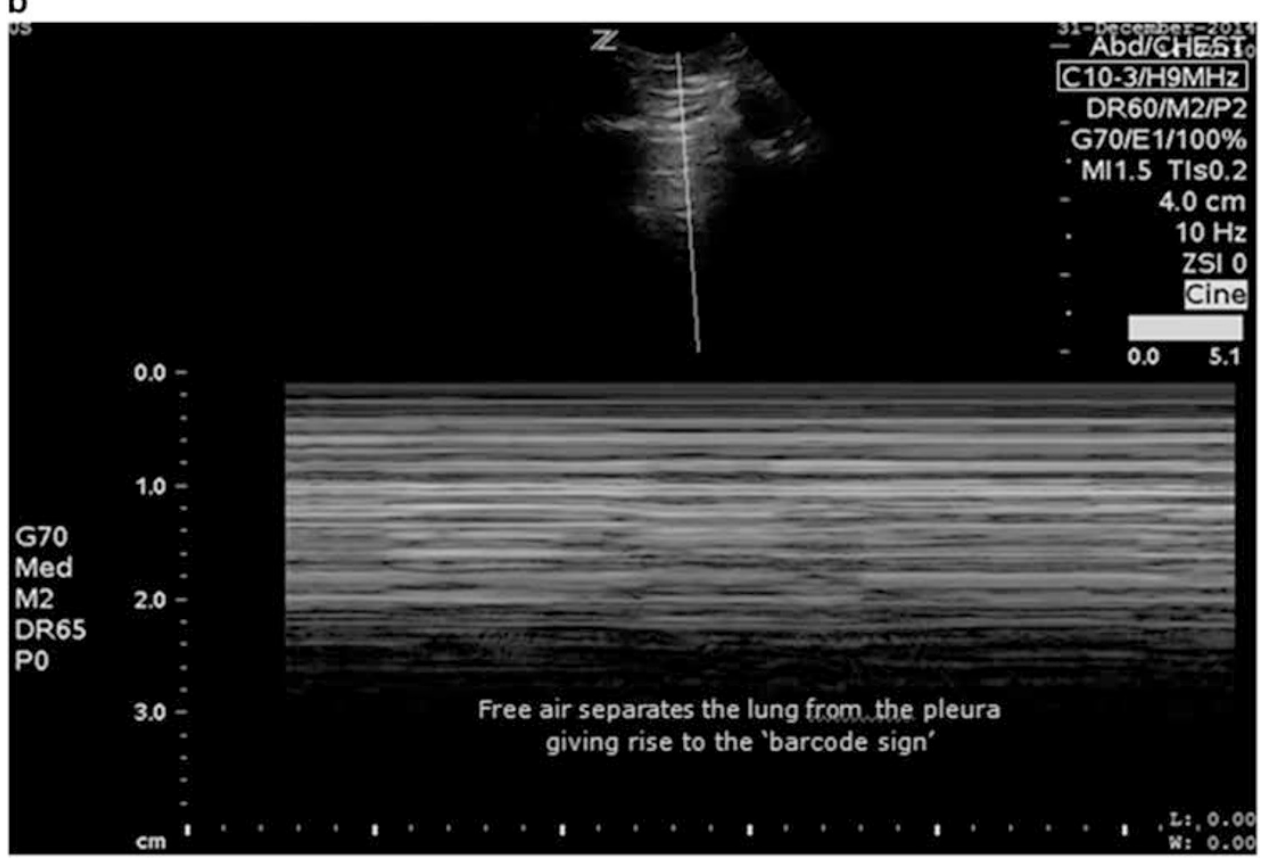

Figure 8. (a) Pneumothorax with 'Barcode Sign' ( $14 \mathrm{MhHz}$ probe). 'Barcode sign' indicates the absence of the lung sliding due to pneumothorax in this neonate. Higher-frequency probe (above $10 \mathrm{MHz}$ ) may demonstrate the 'lines of the barcode' slightly blurred. (b) Pneumothorax with 'Barcode Sign' (10 MhHz probe). Lowering the ultrasound probe frequency to $10 \mathrm{MHz}$ effectively increases the image definition of the 'barcode lines'.

It appears as a very subtle lung sliding created by the beating heart where the beats get transmitted through the atelectatic lung toward the pleura (Supplementary Video S4). Lung pulse is present in $50 \%$ of patients with pneumonia as well. Static air bronchograms are universal, whereas dynamic air bronchograms appear in $16.7 \%$ of neonates with atelectasis (Figure 5). Study of 80 neonates with atelectasis and 50 healthy controls found sensitivity of LUS to be $100 \%$, whereas chest X-rays were only $75 \%$ sensitive. ${ }^{37}$ In adults, dynamic air bronchograms may rule out atelectasis but not in neonates. ${ }^{38}$ Therefore, clinical correlation is recommended to further differentiate pneumonia from atelectasis.
Meconium aspiration syndrome

Meconium aspiration syndrome is a rare but potentially lifethreatening cause of neonatal respiratory distress. LUS in meconium aspiration syndrome has not been widely studied. It shows a wide spectrum of image patterns that depend on the disease severity. Main signs, observed in all patients, are lung consolidations with irregular margins and air bronchograms found in all patients. As expected, they are unevenly distributed inside the same lung and contralaterally (Figure 10). In a recent study enrolling 117 neonates with meconium aspiration 


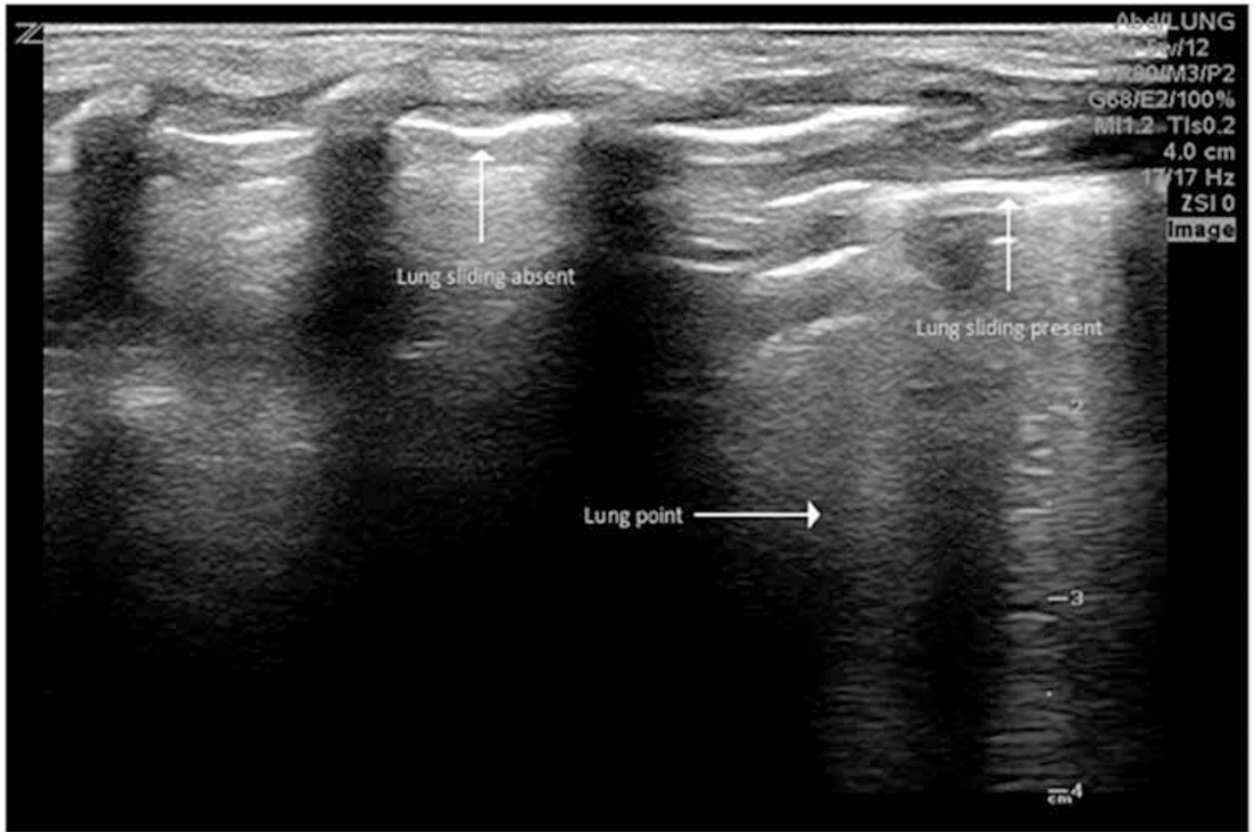

Figure 9. Lung ultrasound of a neonate with pneumothorax showing a clear transitional zone between normal lung sliding (lower lung) and absent lung sliding (upper lung).

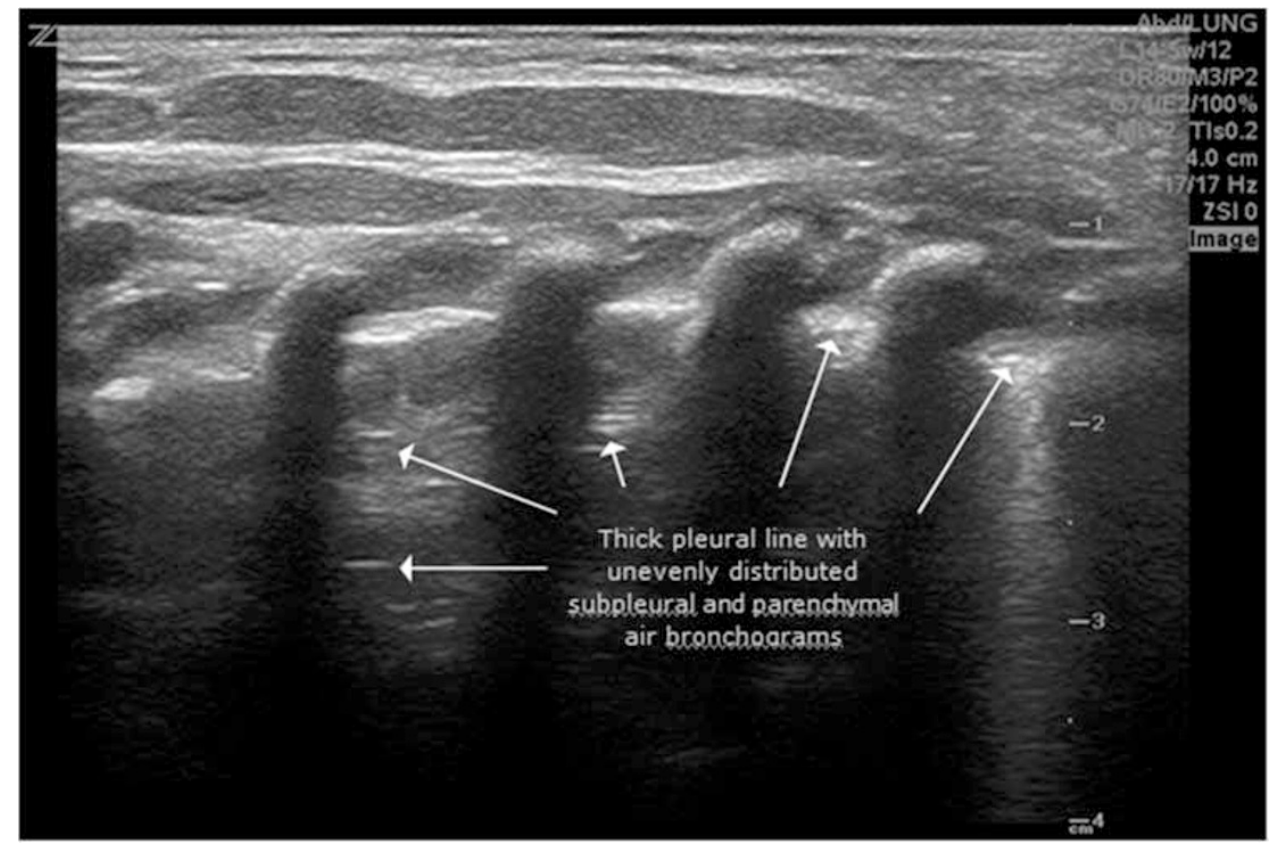

Figure 10. Meconium aspiration syndrome. Lung ultrasound (LUS) of full-term infant showing thickened pleural line with irregular and unevenly distributed extensive atelectasis caused by meconium plugging.

syndrome and 100 healthy controls, these characteristics have been found to be $100 \%$ sensitive and specific. ${ }^{16}$ Other nonspecific findings are disappearance of A-lines, presence of B-lines and thickened and irregular pleura. Large enough atelectasis caused by meconium may cause absence of lung sliding. Because of the meconium redistribution and dynamic character of the disease, these patterns may change LUS imaging of the same area over time. Observed findings correspond well with the chest X-rays. ${ }^{39}$
Bronchopulmonary dysplasia

Chronic lung disease or BPD is characterized by bilateral changes in both the pleural line and the lung itself. The pleural line appears thick with scattered small consolidations under it (Figure 11). Lung parenchyma shows non-homogenous picture that varies in severity from 'white lung' to B-lines that are coalescent or interposed with some spared areas. ${ }^{8}$ Recently, a study that examined 50 infants clinically diagnosed with BPD found that onethird of them actually had some other disease processes 


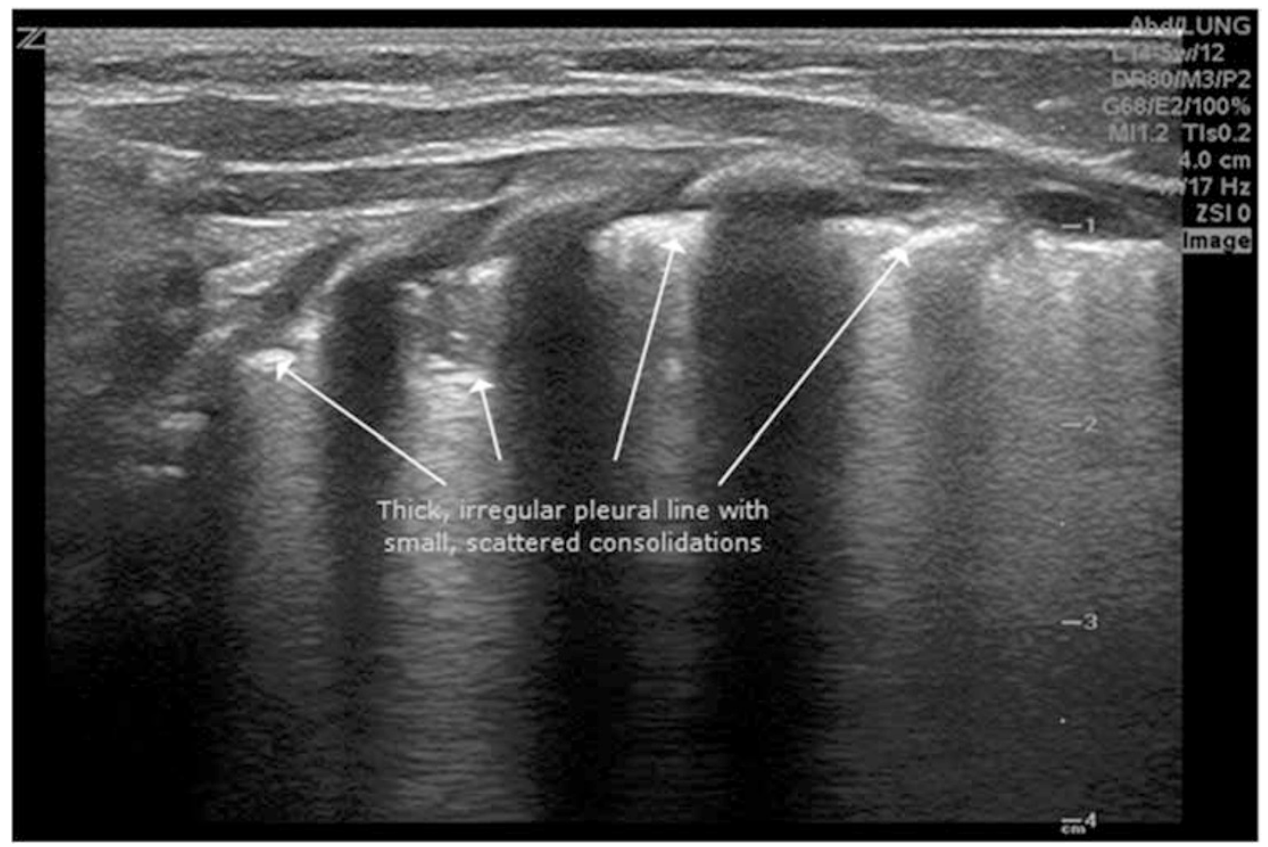

Figure 11. Bronchopulmonary dysplasia. Lung ultrasound (LUS) of a 3-month-old infant born at 24 weeks' gestational age showing bilateral, non-uniform changes in both pleural line and parenchyma. The pleural line is thickened with subpleural consolidations of different sizes. Presence of B-lines represents pulmonary edema due to typical 'leaky capillaries'.

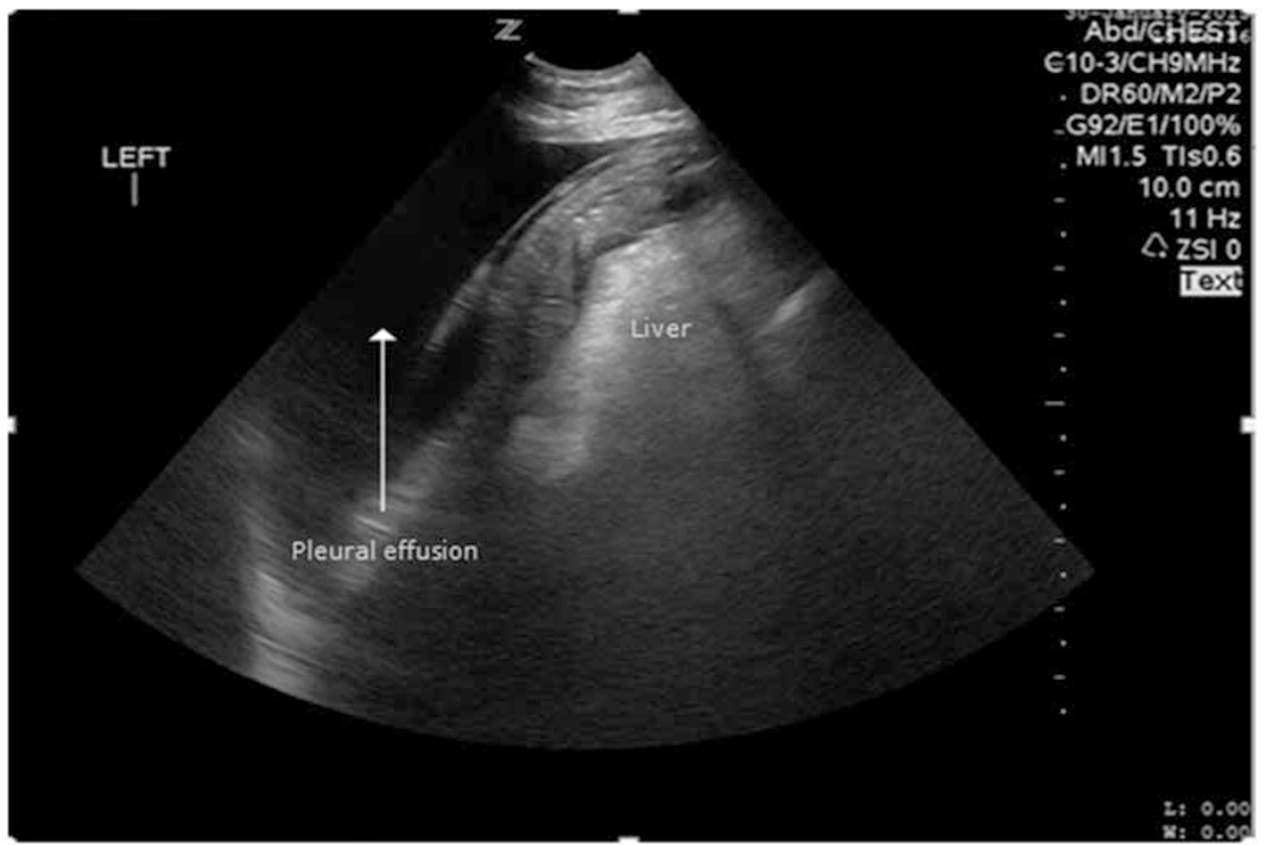

Figure 12. Pleural effusion. Pleural effusion appears as an anechoic space between the visceral and parietal pleura. Further, ultrasound allows identification of the adjacent structures: diaphragm, liver or spleen.

(atelectasis, pneumonia and pulmonary edema) that was an underlying reason for $\mathrm{O}_{2}$ dependency. After these causes were addressed many infants improved significantly or had a complete resolution to their lung symptoms. This study not only supports the use of the LUS in the neonatal intensive care unit but also offers an opportunity for a possible revision of the BPD diagnostic criteria. ${ }^{40}$ Another study found that neonates who did not have a BPD pattern on the LUS beyond day 9 of life were unlikely to develop BPD later. $^{41}$
Pleural effusion

The appearance of fluid in the neonatal pleural space follows the same rules described in the adult literature. The fluid is anechoic (black) and accumulates in the most dependent areas. Typical anatomic boundaries that surround the effusion in an upright patient are the lung surface line, the inside of the chest wall and the diaphragm (Figure 12). This phenomenon is due to the gravitational forces. If the lung is compressed by the fluid, it will create lung flapping or 'jellyfish sign' (Figure 13 and 


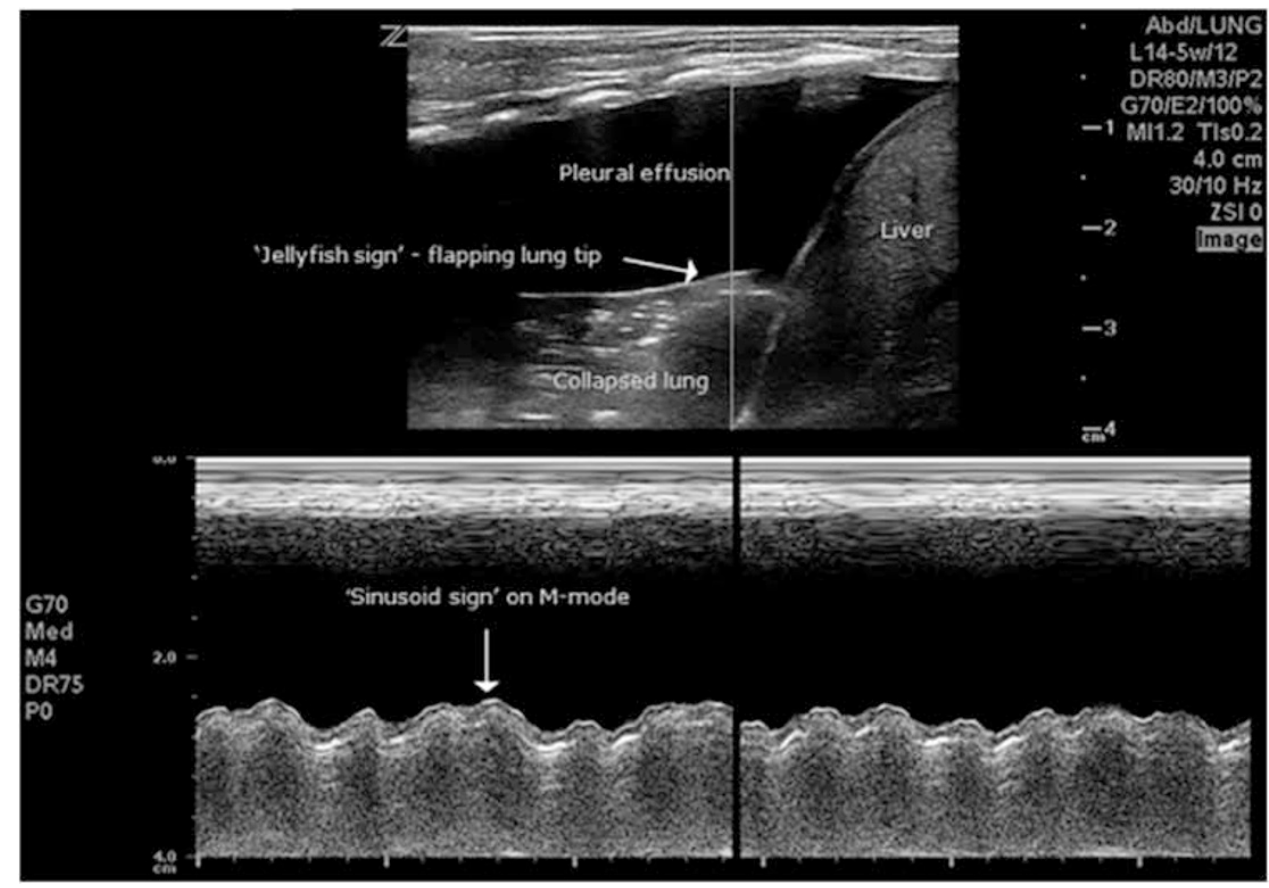

Figure 13. 'Jellyfish sign' and 'Sinusoid Sign.' B-mode of a neonate with a large pleural effusion (upper). Lung is partially collapsed with the lung tip flapping freely in the effusion creating 'jellyfish sign'. M-mode of the same patient showing 'sinusoid sign' as the lung moves towards and away from the pleural line with inspiration and expiration (lower).

Supplementary Video S5). In M-mode, with each respiratory cycle the lung surface line will move toward the pleural line creating a specific 'sinusoid sign' (Figure 13 and Supplementary Video S5). Another common sign is the movement of the aerated lung over the pleural effusion during inspiration. This is so-called 'curtain sign' (Figure 14 and Supplemental Video S6). In supine patients, US probe placed over the posterior axillary line and aimed centrally will create a 'quad sign' if pleural effusion is present. Quad sign has four boundaries: upper border is pleural line, side borders are created by the adjacent posterior shadowing of the ribs and the lower border that belongs to the lung surface line. ${ }^{6}$ Detection of pleural effusion by chest X-rays requires a minimum of $150 \mathrm{ml}$ of fluid, although US can detect effusions as small as $5-10 \mathrm{ml}^{42}$ As expected, assessed in 116 patients, LUS was much more sensitive and specific than chest X-rays in diagnosing pleural effusions, 93 and $83 \%$, respectively. ${ }^{43,44}$ Lastly, US can distinguish between transudate (simple effusion) and exudate (complex effusion) based on the absence or presence of the echoic cellular elements.

\section{FUNCTIONAL NEONATAL LUS STUDIES}

Recent randomized controlled trial in 40 children found that general anesthesia-induced atelectasis may be diagnosed with LUS and ameliorated timely with the use of positive endexpiratory pressure. Atelectotrauma is particularly deleterious to the immature, developing lung. Therefore, LUS may help instituting lung-recruiting maneuvers sooner, especially in the most sensitive group of preterm infants with RDS. ${ }^{45}$ Moreover, a recent study in 49 neonates confirmed that LUS has been found to have much better sensitivity, specificity, PPV and NPV than the chest $\mathrm{X}$-ray in diagnosing pneumothorax. ${ }^{46} \mathrm{~A}$ case report describes a successful emergent aspiration of pneumothorax diagnosed with LUS in a neonate. In this particular case, transillumination examination was negative and chest $\mathrm{X}$-ray arrived 20 min later. ${ }^{47}$ Evidently, availability of POC-US accelerates pneumothorax evacuation and potentially prevents development of intraventricular hemorrhage that has relatively well-established temporal relationship to pneumothorax. ${ }^{48}$ Several well-designed functional studies used LUS to describe various important points in the neonatal respiratory pathophysiology. Two of these studies conducted in large number of late-preterm and term neonates described LUS patterns characteristic of the postnatal fluid clearance, consequent changes in the lung compliance and eventual need for admission to neonatal intensive care unit for respiratory support. These patterns are reproducible with PPV of $100 \%$ and NPV of $97 \% .{ }^{12,15}$ Further, in 130 premature infants on continuous positive airway pressure, the LUS score correlated well with all indices of oxygenation and proved to be reliable in predicting the need for surfactant administration. ${ }^{14}$ In addition, two studies that examined more than 150 premature infants found that neonatal LUS appears to be a much better tool than chest X-rays in predicting a failure of non-invasive ventilation and the need for mechanical ventilation. ${ }^{10,11}$ One study examined sonographic findings in 105 infants with RDS and their timing in relation to the development of BPD. It found that on LUS retrodiaphragmatic hyperechogenicity present beyond 17 days of life accurately predicts those who will develop BPD. ${ }^{9}$ Use of LUS has also been described in the follow-up of postoperative lung complications in neonates with congenital heart disease. ${ }^{13} \mathrm{~A}$ recent interesting case from an emergency department describes use of LUS in diagnosis of congenital diaphragmatic hernia in a 12-day-old infant with respiratory distress who was already discharged home. On the affected side lung sliding was present only in the upper one-third of the chest with obvious intestinal peristalsis and loops of bowel visualized in the lower part of the chest. ${ }^{49}$

\section{DISCUSSION AND FUTURE PERSPECTIVES}

Neonatal LUS imaging follows the same principles described in the adult LUS literature. On the other hand, specific neonatal respiratory pathology allows for additional descriptive and, more than ever, non-invasive functional research opportunities that 


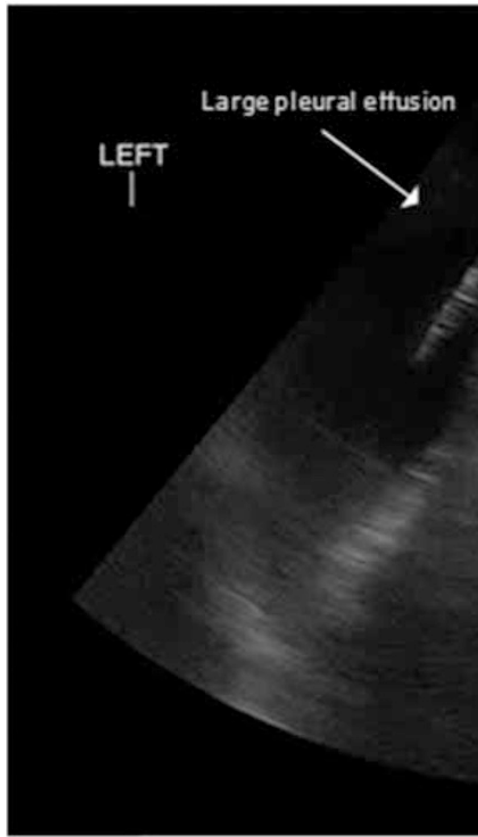

Abd/बक्तs

$\mathrm{G} 10.3 / \mathrm{CH} 9 \mathrm{MHz}$

DR60/M2/P2

G92/E1/100\%

Mi1.5 Tis0.6

$10.0 \mathrm{~cm}$

$11 / 11 \mathrm{~Hz}$

C. ZSIO

Text

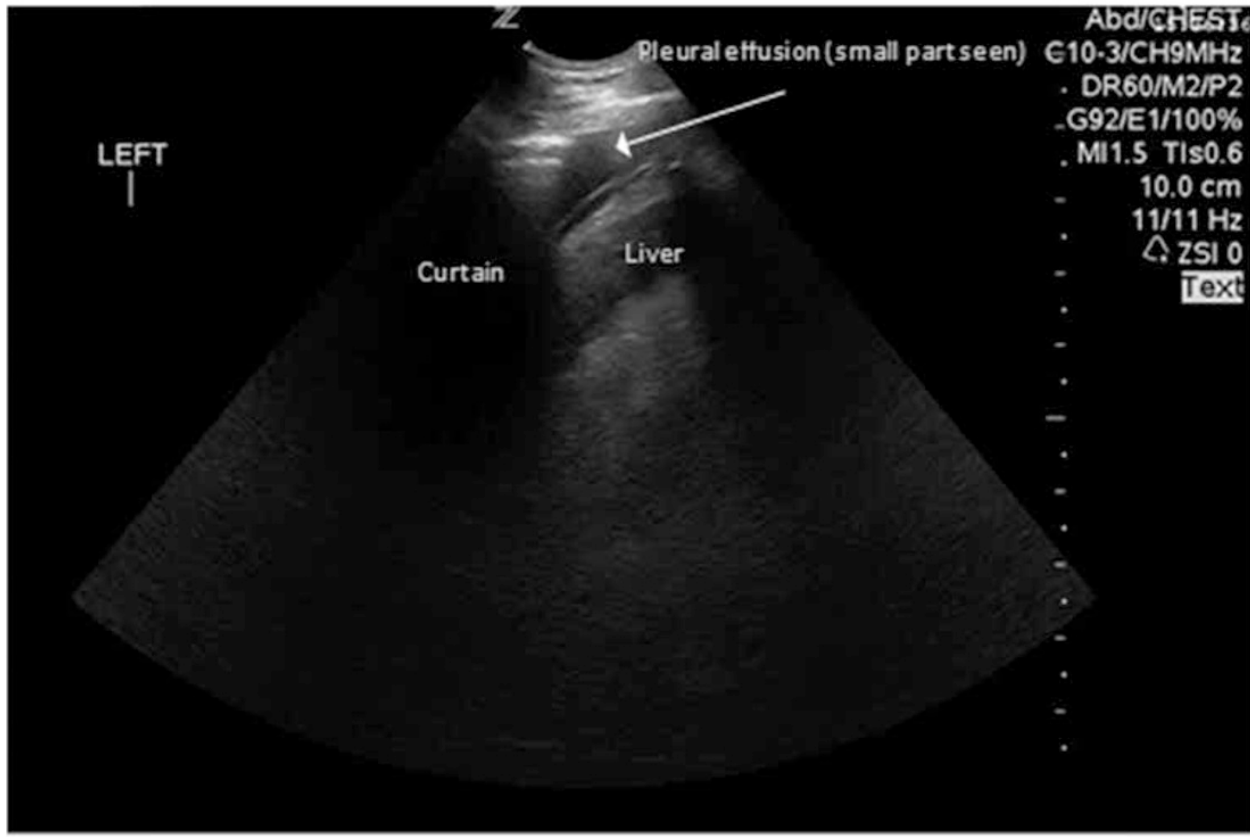

Figure 14. 'Curtain Sign.' In a neonate with the left pleural effusion the image appears to vanish with inspiration. It is due to the expanding lung being briefly interposed between the probe and the effusion therefore creating the 'curtain sign'.

should further our understanding in this field. An especially exciting field for further research may be to integrate dynamic POC-US into assessing how changes in compliance, lung expansion and positive end-expiratory pressure may affect patent ductus arteriosus flow and consequently systemic blood flow. Future studies should address whether advantages of LUS confer improved long-term outcomes. Although LUS has been found to be quick and convenient imaging modality, it is important to emphasize that the growing body of evidence finds it to be accurate and reliable with few inherent limitations. These limitations stem from the fact that some LUS findings may not be completely reproducible by less experienced operators. Nevertheless, in one study, interobserver agreement among practitioners with different levels of experience was substantially high. ${ }^{50}$ Expansion of POC-US use in general prompts well-defined guidelines, standards and credentialing processes pertaining to LUS use and education. Validated decision-making algorithms are very useful in organizing our approach to diagnostic challenges. We believe that the LUS algorithms offered here may serve as a clinical imaging guideline and a valuable complement to the history and physical examination.

\section{CONFLICT OF INTEREST}

The authors declare no conflict of interest.

\section{ACKNOWLEDGEMENTS}

We specially thank Dr Jing Liu for his mentorship and Dr Richard Schanler who helped edit this article. 


\section{REFERENCES}

1 Hall EJ. Lessons we have learned from our children: cancer risks from diagnostic radiology. Pediatr Radiol 2002; 32(10): 700-706.

2 Lichtenstein D. Lung ultrasound in acute respiratory failure an introduction to the BLUE-protocol. Minerva Anestesiol 2009; 75(5): 313-317.

3 Cattarossi L. Lung ultrasound: its role in neonatology and pediatrics. Early Hum Dev 2013; 89(Suppl 1): S17-S19.

4 Lichtenstein D, Goldstein I, Mourgeon E, Cluzel P, Grenier P, Rouby JJ. Comparative diagnostic performances of auscultation, chest radiography, and lung ultrasonography in acute respiratory distress syndrome. Anesthesiology 2004; 100 (1): 9-15.

5 Xirouchaki N, Magkanas E, Vaporidi K, Kondili E, Plataki M, Patrianakos A et al. Lung ultrasound in critically ill patients: comparison with bedside chest radiography. Intensive Care Med 2011; 37(9): 1488-1493.

6 Lichtenstein DA, Mauriat P. Lung ultrasound in the critically ill neonate. Curr Pediatr Rev 2012; 8(3): 217-223.

7 Liu J. Lung ultrasonography for the diagnosis of neonatal lung disease. J Matern Fetal Neonatal Med 2014; 27(8): 856-861.

8 Copetti R, Cattarossi L. Lung ultrasound in newborns, infants, and children. In: Mathis G (ed). Chest Sonography, 3rd edn. Springer: Berlin, Heidelberg: New York, 2011.

9 Avni EF, Cassart M, de Maertelaere V, Rypens F, Vermeylen D, Gevenois PA. Sonographic prediction of chronic lung disease in the premature undergoing mechanical ventilation. Pediatr Radiol 1996; 26(7): 463-469.

10 Raimondi F, Migliaro F, Sodano A, Ferrara T, Lama S, Vallone G et al. Use of neonatal chest ultrasound to predict noninvasive ventilation failure. Pediatrics 2014; 134(4): e1089-e1094.

11 Rodriguez-Fanjul J, Balcells C, Aldecoa-Bilbao V, Moreno J, Iriondo M. Lung ultrasound as a predictor of mechanical ventilation in neonates older than 32 weeks. Neonatology 2016; 110(3): 198-203.

12 Raimondi F, Migliaro F, Sodano A, Umbaldo A, Romano A, Vallone G et al. Can neonatal lung ultrasound monitor fluid clearance and predict the need of respiratory support? Crit Care 2012; 16(6): R220.

13 Vitale V, Ricci Z, Cogo P. Lung ultrasonography and pediatric cardiac surgery: first experience with a new tool for postoperative lung complications. Ann Thorac Surg 2014; 97(4): e121-e124.

14 Brat R, Yousef N, Klifa R, Reynaud S, Shankar Aguilera S, De Luca D. Lung ultrasonography score to evaluate oxygenation and surfactant need in neonates treated with continuous positive airway pressure. JAMA Pediatr 2015; 169(8): e151797.

15 Martelius L, Suvari L, Janer C, Helve O, Kaskinen A, Kirjavainen T et al. Lung ultrasound and static lung compliance during postnatal adaptation in healthy term infants. Neonatology 2015; 108(4): 287-292.

16 Liu J, Cao HY, Fu W. Lung ultrasonography to diagnose meconium aspiration syndrome of the newborn. J Int Med Res 2016; 44: 1534-1542.

17 Lichtenstein DA, Menu Y. A bedside ultrasound sign ruling out pneumothorax in the critically ill. Lung sliding. Chest 1995; 108(5): 1345-1348.

18 Lichtenstein DA, Meziere G, Lascols N, Biderman P, Courret JP, Gepner A et al. Ultrasound diagnosis of occult pneumothorax. Crit Care Med 2005; 33(6): 1231-1238.

19 Volpicelli G, Caramello V, Cardinale L, Mussa A, Bar F, Frascisco MF. Detection of sonographic B-lines in patients with normal lung or radiographic alveolar consolidation. Med Sci Monit 2008; 143: Cr122-Cr128.

20 Lichtenstein DA, Lascols N, Meziere G, Gepner A. Ultrasound diagnosis of alveolar consolidation in the critically ill. Intensive Care Med 2004; 30(2): 276-281.

21 Copetti R, Cattarossi L. The 'double lung point': an ultrasound sign diagnostic of transient tachypnea of the newborn. Neonatology 2007; 91(3): 203-209.

22 Liu J, Wang Y, Fu W, Yang CS, Huang JJ. Diagnosis of neonatal transient tachypnea and its differentiation from respiratory distress syndrome using lung ultrasound. Medicine 2014; 93(27): e197.

23 Liu J, Chen XX, Li XW, Chen SW, Wang Y, Fu W. Lung ultrasonography to diagnose transient tachypnea of the newborn. Chest 2016; 149(5): 1269-1275.

24 Vergine M, Copetti R, Brusa G, Cattarossi L. Lung ultrasound accuracy in respiratory distress syndrome and transient tachypnea of the newborn. Neonatology 2014; 106(2): 87-93.
25 Avni EF, Braude P, Pardou A, Matos C. Hyaline membrane disease in the newborn: diagnosis by ultrasound. Pediatr Radiol 1990; 20(3): 143-146.

26 Copetti R, Cattarossi L, Macagno F, Violino M, Furlan R. Lung ultrasound in respiratory distress syndrome: a useful tool for early diagnosis. Neonatology 2008; 94(1): 52-59.

27 Bober K, Swietlinski J. Diagnostic utility of ultrasonography for respiratory distress syndrome in neonates. Med Sci Monit 2006; 12(10): Cr440-Cr446.

28 El-Malah HE-DGM, Hany S, Mahmoud MK, Ali AM. Lung ultrasonography in evaluation of neonatal respiratory distress syndrome. Egypt J Radiol Nucl Med 2015; 46(2): 469-474.

29 Liu J, Cao HY, Wang HW, Kong XY. The role of lung ultrasound in diagnosis of respiratory distress syndrome in newborn infants. Iran J Pediatr 2015; 25(1): e323.

30 Lovrenski J. Lung ultrasonography of pulmonary complications in preterm infants with respiratory distress syndrome. Ups J Med Sci 2012; 117(1): 10-17.

31 Lovrenski J, Sorantin E, Stojanovic S, Doronjski A, Lovrenski A. Evaluation of surfactant replacement therapy effects--a new potential role of lung ultrasound. Srp Arh Celok Lek 2015; 143(11-12): 669-675.

32 Sawires HK, Abdel Ghany EA, Hussein NF, Seif HM. Use of lung ultrasound in detection of complications of respiratory distress syndrome. Ultrasound Med Biol 2015; 41(9): 2319-2325.

33 Lichtenstein D, Meziere G, Biderman P, Gepner A. The "lung point": an ultrasound sign specific to pneumothorax. Intensive Care Med 2000; 26(10): 1434-1440.

34 Volpicelli G, Elbarbary M, Blaivas M, Lichtenstein DA, Mathis G, Kirkpatrick AW et al. International evidence-based recommendations for point-of-care lung ultrasound. Intensive Care Med 2012; 38(4): 577-591.

35 Caiulo VA, Gargani L, Caiulo S, Fisicaro A, Moramarco F, Latini G et al. Lung ultrasound characteristics of community-acquired pneumonia in hospitalized children. Pediatr Pulmonol 2013; 48(3): 280-287.

36 Liu J, Liu F, Liu Y, Wang HW, Feng ZC. Lung ultrasonography for the diagnosis of severe neonatal pneumonia. Chest 2014; 146(2): 383-388.

37 Liu J, Chen SW, Liu F, Li QP, Kong XY, Feng ZC. The diagnosis of neonatal pulmonary atelectasis using lung ultrasonography. Chest 2015; 147(4): 1013-1019.

38 Lichtenstein D, Meziere G, Seitz J. The dynamic air bronchogram. A lung ultrasound sign of alveolar consolidation ruling out atelectasis. Chest 2009; 135(6): $1421-1425$.

39 Piastra M, Yousef N, Brat R, Manzoni P, Mokhtari M, De Luca D. Lung ultrasound findings in meconium aspiration syndrome. Early Hum Dev 2014; 90(Suppl 2): S41-S43.

40 Liu J, Chen SW, Liu F, Wang Y, Kong XY, Li QP et al. BPD, not BPD, or iatrogenic BPD: findings of lung ultrasound examinations. Medicine 2014; 93(23): e133.

41 Pieper $\mathrm{CH}$, Smith J, Brand EJ. The value of ultrasound examination of the lungs in predicting bronchopulmonary dysplasia. Pediatr Radiol 2004; 34(3): 227-231.

42 Colins JD, Burwell D, Furmanski S, Lorber P, Steckel RJ. Minimal detectable pleural effusions. A roentgen pathology model. Radiology 1972; 105(1): 51-53.

43 Gryminski J, Krakowka P, Lypacewicz G. The diagnosis of pleural effusion by ultrasonic and radiologic techniques. Chest 1976; 70(1): 33-37.

44 Kelbel C, Borner N, Schadmand S, Klose KJ, Weilemann LS, Meyer J et al. [Diagnosis of pleural effusions and atelectases: sonography and radiology compared]. Rofo 1991; 154(2): 159-163.

45 Song IK, Kim EH, Lee JH, Ro S, Kim HS, Kim JT. Effects of an alveolar recruitment manoeuvre guided by lung ultrasound on anaesthesia-induced atelectasis in infants: a randomised, controlled trial. Anaesthesia 2017: 2017: 214-222.

46 Cattarossi L, Roberto Copetti R, Brusa G, Pintaldi S. Lung Ultrasound Diagnostic Accuracy in Neonatal Pneumothorax. Canadian Respiratory Journal. 2016; 2016: 6515069.

47 Migliaro F, Sodano A, Capasso L, Raimondi F. Lung ultrasound-guided emergency pneumothorax needle aspiration in a very preterm infant. BMJ Case Rep 2014; 2014.

48 Hill A, Perlman JM, Volpe JJ. Relationship of pneumothorax to occurrence of intraventricular hemorrhage in the premature newborn. Pediatrics 1982; 69(2): 144-149.

49 Rankin JH, Elkhunovich M, Seif D, Chilstrom M. Point-of-care ultrasound diagnosis of diaphragmatic hernia in an infant with respiratory distress. Pediatr Emerg Care 2016; 32(10): 731-733.

50 Brusa G, Savoia M, Vergine M, Bon A, Copetti R, Cattarossi L. Neonatal lung sonography: interobserver agreement between physician interpreters with varying levels of experience. J Ultrasound Med 2015; 34(9): 1549-1554.

Supplementary Information accompanies the paper on the Journal of Perinatology website (http://www.nature.com/jp) 